\title{
Differences in the Gait Pattern and Muscle Activity of the Lower Extremities during Forward and Backward Walking on Sand
}

\author{
Chae-Won Kwon'1, Seong Ho Yun', Jung-Won Kwon² \\ 'Department of Public Health Sciences, Graduate School, Dankook University, Cheonan, Republic of Korea; ${ }^{2}$ Department of Physical Therapy, College \\ of Health and Welfare Sciences, Dankook University, Cheonan, Republic of Korea
}

Purpose: The purpose of this study was to compare the spatiotemporal and kinematic gait parameters and muscle activity of the lower extremities between forward walking on sand (FWS) and backward walking on sand (BWS) in normal adults.

Methods: This study was conducted on 13 healthy adults. Subjects performed FWS and BWS and the spatiotemporal and kinematic gait parameters of stride time, stride length, velocity, cadence, step length, stance, swing, double support, and hip range of motion (ROM), knee ROM were measured by a wearable inertial measurement unit system. In addition, the muscle activity of the rectus femoris (RF), biceps femoris (BF), tibialis anterior (TA), and gastrocnemius (GA) was measured.

Results: The stride length, stride velocity, cadence, and step length in the BWS were significantly lower than FWS $(p<0.05)$, and stride time was significantly greater $(p<0.05)$. However, there was no significant difference in the ratio of stance, swing, and double support between the two $(p>0.05)$. The kinematic gait parameters, including hip and knee joint range of motion in BWS, were significantly lower than FWS $(p<0.05)$. The muscle activity of the RF in BWS was significantly higher than FWS $(p<0.05)$, but the muscle activity of the BF, $T A, G A$ did not show any significant differences between the two movements $(p>0.05)$.

Conclusion: A strategy to increase stability by changing the gait parameters is used in BWS, and this study confirmed that BWS was a safe and effective movement to increase RF muscle activity without straining the joints. Therefore, BWS can be recommended for effective activation of the RF.

Keywords: Sand, Backward walking, Rectus femoris

서 론

보행은 안정성과 균형을 유지하며 신체를 전방으로 이동시키는 동작 으로, 엉덩관절, 무릎관절, 발목관절의 굽힘근과 폄근의 상호 작용을 포함한 관절 및 근육의 협응으로 이루어진다.1-4 보행 시 하지는 충격 을 감소시키고 안정성을 제공하기 위한 편심성 수축과 전방으로 신 체를 움직이기 위한 동심성 수축을 하기 때문에 보행 주기동안 일정 한 근활성도를 나타낸다. ${ }^{5}$

이러한 보행은 진행 방향에 따라 앞으로 걷기와 뒤로 걷기로 구분 되며 보행 유형에 따라 동원되는 근육의 수축형태와 활성도가 달라 진다. ${ }^{6}$ 예를 들어, 장딴지근은 앞으로 걷기에서 전방으로 신체를 나아 가기 위한 가속기 역할을 하지만 뒤로 걷기에서는 발과 발목의 움직 임을 감속하는 기능을 하고, 넙다리네갈래근은 앞으로 걷기 시 편심 성 수축을 하며 감속기 역할을 하는 반면에 뒤로 걷기 시 동심성 수

Received Jan 28, 2022 Revised Feb 11, 2022

Accepted Feb 17, 2022

Corresponding author Jung-Won Kwon

E-mail kjwonpt@hanmail.net
축을 하며 가속기 역할을 한다.-9 앞으로 걷기에 비해 뒤로 걷기는 발 가락이 먼저 지면에 닿기 때문에 무릎에 흡수되는 충격을 감소시켜 관절에 가해지는 스트레스를 줄이고, 몸통 근육과 하지 근육 특히, 넙다리네갈래근의 더 높은 동원과 근활성도를 나타내어 무릎관절 을 안정화시키고, 수행능력을 향상시킨다.10-14 또한, 뒤로 걷기에서는 시각 정보를 통해 지면을 예측할 수 없으며 시각, 고유수용성감각, 안 뜰 감각의 변경된 정보를 재구성하여 균형을 조절하고, 움직임을 제 어하기 때문에 하지 근육의 시너지 효과와 운동 조절을 재구성시켜 하지의 근육을 더 많이 동원하는 이점을 가지고 있다.15,16 이처럼 뒤 로 걷기는 하지 관절에 가해지는 스트레스를 최소화하면서 높은 하 지의 근활성도를 나타내는 이점이 있기 때문에 재활 및 스포츠분야 에서 이용되고 있다. ${ }^{15-17}$

일반적으로 평지나 트레드밀과 같은 안정한 지면에서 보행훈련이 수행되고 있지만, ${ }^{18}$ 최근에는 스팀업(stim-up)매트, ${ }^{19,20}$ 모래 ${ }^{21,22}$ 와 같은
Copylight (C)2022 The Korean Society of Physical Therapy

This is an Open Access article distribute under the terms of the Creative Commons Attribution Non-commercial License (https:// creativecommons.org/license/by-nc/4.0.) which permits unrestricted non-commercial use, distribution, and reproduction in any medium, provided the original work is properly cited. 
다양한 지면에서 수행되고 있다. 이 중에서 모래지면은 자연환경을 이용하기 때문에 어디서든 접근하기 쉬운 방법이며, ${ }^{23}$ 연속적인 불안 정한 지면을 제공함으로 균형 유지를 위해 하지의 높은 근활성도를 이끌어낼 수 있다.22 모래 위에서 보행 시 증가된 발의 접촉 시간은 신 장-단축 주기의 효율성을 감소시키고, 탄성에너지의 잠재력을 줄이 기 때문에 더 높은 근활성도를 보인다. ${ }^{24-26}$ 또한, 모래지면은 유동적이 고 가변적인 표면기이기 때문에 모래지면에서 보행 시 안정성을 유지 하기 위해 보행속도와 한발짝길이를 감소시키고, 한발짝시간과 양하 지지지기 시간을 증가시키는 보행 전략이 사용된다.24,28,29 특히 모래 는 충격 완화 성질로 인해 근육과 관절에 걸리는 부하를 감소시켜 부 상 위험을 줄이는 이점을 가지고 있다.30,31

선행연구들에서 모래지면에서 앞으로 걷기는 안정된 지면에서 앞 으로 걷기에 비해 높은 하지의 근활성도를 나타내며, 보행 변수에 영 향을 미친다고 보고하였다. ${ }^{21}$ 또한 안정된 지면에서 뒤로 걷기는 관절 에 가해지는 스트레스를 최소화하면서 높은 근활성도를 이끄는 장 점이 있다. ${ }^{17}$ 하지만, 안정된 지면에서 뒤로 걷기의 장점이 있음에도 모 래지면에서 뒤로 걷기의 보행 변수에 대한 선행연구는 있지만, 근활 성도와 보행 변수를 함께 측정한 연구는 부족하다. 따라서 본 연구의 목적은 정상 성인을 대상으로 모래지면에서 앞으로 걷기와 뒤로 걷 기 시 보행의 시공간적 요소 및 운동형상학적 특성과 하지의 근활성 도를 비교하는 것이다.

\section{연구 방법}

\section{1. 연구대상}

본 연구는 보행장애가 없는 건강한 성인 13 명을 대상으로 하였다. 연 구 대상자 수는 $\mathrm{G}^{*}$ Power 3.1 을 이용하여 0.80 의 통계학적 검증력을 얻 기 위해 최소 13 명의 표본 크기가 산출되었다. ${ }^{32,33}$ 대상자 선정 기준은 1) 최근 6개월 이내 하지 관절에 상해를 입지 않은 자, 2) 허리통증 및 척추 관련 질환이 없는 자, 3) 모래지면에서 앞으로 걷기와 뒤로 걷기 수행에 영향을 미치는 정적 및 동적 균형장애가 없는 자로 하였다. 모 든 대상자는 연구에 관하여 충분한 설명을 듣고, 연구참여에 대한 자 발적인 서면동의를 하였다. 본 연구는 기관 연구 심의위원회에서 승 인하여 진행하였다(DKU 2019-04-022).

\section{2. 실험방법}

1) 측정도구

(1) 보행분석시스템

보행의 시공간적 요소 및 운동형상학적 특성을 측정하기 위해 가속 도계(accelerometers), 자력계(magnetometers), 자이로스코프(gyroscopes)로 이루어진 5 개의 착용식 센서 $(5.0 \mathrm{~cm} \times 4.2 \mathrm{~cm} \times 1.2 \mathrm{~cm})$ 로 구
성된 휴대용 보행분석시스템(LEGSys+, BioSensics, USA)을 사용하였 다. 34,35 각각의 센서는 위뒤엉덩뼈가시, 양쪽 무릎관절 위앞 $3 \mathrm{~cm}$, 양 쪽 발목관절 위앞 $3 \mathrm{~cm}$ 에 부착하였으며, 내장된 센서를 기반으로 전 방향의 벡터를 수집하였다. ${ }^{36}$ 모든 데이터는 실시간으로 블루투스가 장착된 컴퓨터를 통하여 수집되었으며 표본추출률(sampling rate)은 $100 \mathrm{~Hz}$ 이었다. 본 연구에서 보행의 시공간적 요소는 한걸음시간 (stride time), 한걸음길이(stride length), 보행속도(velocity), 보행률(cadence), 한발짝길이(step length), 디딤기(stance), 흔듦기(swing) 및 양하 지지지기(double support)의 비율을 측정하였으며, 운동형상학적 특 성으로는 엉덩관절과 무릎관절의 관절가동범위를 측정하였다.

\section{(2) 표면 근전도(Electromyograph, EMG)}

앞으로 걷기 및 뒤로 걷기 시 하지의 근활성도를 측정하기 위해 표면 근전도 장비(NORAXON Myosystem EMG, Noraxon Inc., US)를 사용 하였다. 표면 근전도 신호에 대한 피부 저항을 줄이기 위해 면도기를 사용하여 피부의 털을 제거하고, 알코올 솜을 사용하여 피부 표면을 세척하였다. 근전도의 표면전극은 대상자의 비우세측 다리의 넙다리 곧은근(Rectus femoris), 넙다리두갈래근(Biceps femoris), 앞정강근 (Tibialis anterior), 장딴지근(Gastrocnemius)에 부착하였다. 각 근육의 전극 부착 부위는 다음과 같다. 1) 넙다리곧은근은 위앞엉덩뼈가시 (anterior superior iliac spine)와 무릎뼈를 이은 선의 중간지점, 2) 넙다 리두갈래근은 궁둥뼈결절(ischial tuberosity)과 정강뼈의 가쪽위관절 융기를 이은 선의 중간지점, 3) 장딴지근은 외측 종아리의 중앙 지점, 4) 앞정강근은 정강뼈 능선을 기준으로 바깥쪽으로 $2 \mathrm{~cm}$ 지점으로 설 정하였다. ${ }^{37}$

표면 근전도 측정 장비는 무선 송신기와 연결되어 주파수를 전송 하여 데이터를 수집하였다. 근전도 신호의 주파수 대역폭은 20-450 $\mathrm{Hz}$ 로 설정하였고, 샘플링 주파수는 $1,000 \mathrm{~Hz}$ 로 하였다. 각각의 조건 에 따른 보행을 수행하는 동안 시작과 끝 지점의 각 $1 \mathrm{~m}$ 를 제외하고 측정된 신호를 분석하였다. 실험에서 측정된 근전도 신호는 Root mean square (RMS)값으로 처리하였으며, RMS값은 일반지면에서 앞 으로 걷기를 기준 수축(Reference Voluntary Contraction, RVC)으로 두 어 \%RVC로 정규화하였다.

\section{2) 실험절차}

실제 모래지면과 유사한 환경을 조성하기 위해 가로 $1 \mathrm{~m}$, 세로 $5 \mathrm{~m}$, 높 이 $40 \mathrm{~cm}$ 의 보행 프레임을 제작하였으며, 프레임 안에 모래를 $30 \mathrm{~cm}$ 깊이로 채워 넣었다. 실험 전 모래지면 환경의 적응을 위해 특수 제작 된 프레임 공간에서 특별한 지시없이 평소 습관과 방식으로 5 분간 보 행을 실시하였다. 이후 대상자는 보행 시작 신호에 따라 앞으로 걷기 또는 뒤로 걷기를 실시하였고 끝 지점에 도달하면 걷기를 멈추고 정 
Table 1. The comparison of spatiotemporal parameters according to forward and backward walking

\begin{tabular}{lrcc}
\hline & FW & BW & p \\
\hline Stride time (s) & $1.36 \pm 0.10$ & $1.53 \pm 0.21$ & $0.003^{*}$ \\
Stride length (m) & $1.10 \pm 0.12$ & $0.76 \pm 0.80$ & $0.001^{*}$ \\
Stride velocity (m/s) & $0.82 \pm 0.14$ & $0.53 \pm 0.09$ & $0.001^{*}$ \\
Cadence (steps/min) & $89.34 \pm 6.28$ & $82.87 \pm 10.66$ & $0.009^{*}$ \\
Left step length (m) & $0.55 \pm 0.05$ & $0.38 \pm 0.06$ & $0.001^{*}$ \\
Right step length (m) & $0.54 \pm 0.86$ & $0.38 \pm 0.04$ & $0.002^{*}$ \\
Left stance (\%) & $61.87 \pm 1.74$ & $61.00 \pm 2.53$ & 0.249 \\
Right stance (\%) & $61.03 \pm 2.06$ & $60.52 \pm 2.39$ & 0.422 \\
Left swing (\%) & $38.13 \pm 1.74$ & $39.00 \pm 2.53$ & 0.249 \\
Right swing (\%) & $38.97 \pm 2.06$ & $39.49 \pm 2.39$ & 0.422 \\
Total double support (\%) & $22.90 \pm 3.28$ & $21.51 \pm 3.71$ & 0.345 \\
\hline
\end{tabular}

Mean $\pm S D$.

FW: Forward Walking, BW: Backward Walking.

${ }^{*}$ significant difference between FW and BW $(p<0.05)$.

Table 2. The comparison of kinematic parameters according to forward and backward walking

\begin{tabular}{lclc}
\hline & FW & \multicolumn{1}{c}{ BW } & p \\
\hline Left Knee ROM $\left(^{\circ}\right)$ & $68.52 \pm 9.88$ & $52.47 \pm 9.40$ & $0.002^{*}$ \\
Right Knee ROM $\left(^{\circ}\right)$ & $67.13 \pm 6.50$ & $53.77 \pm 11.11$ & $0.002^{*}$ \\
Left Hip ROM $\left(^{\circ}\right)$ & $49.58 \pm 7.90$ & $37.35 \pm 5.05$ & $0.001^{*}$ \\
Right Hip ROM $\left(^{\circ}\right)$ & $49.35 \pm 6.74$ & $37.65 \pm 5.07$ & $0.001^{*}$ \\
\hline
\end{tabular}

Mean \pm SD.

FW: Forward Walking, BW: Backward Walking, ROM: Range of motion.

*significant difference between FW and BW $(p<0.05)$.

적 기립자세를 유지하였다. 앞으로 걷기와 뒤로 걷기의 순서는 무작 위로 하였으며 앞으로 걷기와 뒤로 걷기 각 1 회를 1 세트로 하여 총 3 세트를 실시하였다. 앞으로 걷기와 뒤로 걷기 간 휴식시간은 30 초를 제공하였고, 세트 간 휴식시간은 3 분을 제공하였다. 모든 데이터는 보행의 시작점으로부터 $1 \mathrm{~m}$ 와 끝나는 지점으로부터 $1 \mathrm{~m}$ 를 제외한 총 $3 \mathrm{~m}$ 에서 수집하였으며, 앞으로 걷기와 뒤로 걷기를 각 3 회 측정한 값의 평균값을 결과값으로 사용하였다.

\section{3. 자료분석}

본 연구에서 수집된 모든 데이터는 Windows SPSS version 25.0 (IBM Co., USA) 프로그램을 이용하여 분석하였다. 연구 대상자의 일반적인 특성인 연령, 신장, 몸무게는 기술통계를 실시하였고, 앞으로 걷기와 뒤로 걷기 조건에 따른 하지 근활성도와 보행의 시공간적 요소 및 운 동형상학적 특성을 비교하기 위해 정규성 검정(Shapiro-Wilk test)에 따라 윌콕슨 부호 순위 검증(Wilcoxon's signed-ranks test)을 실시하였 다. 유의수준은 $\mathrm{p}=0.05$ 로 설정하였다.

\section{결 과}

본 연구에 참가한 대상자들의 성별, 평균 연령, 평균 신장, 평균 체중
Table 3. The comparison of muscle activity according to forward and backward walking

(Unit: \%RVC)

\begin{tabular}{lccc}
\hline & FW & BW & p \\
\hline Rectus femoris & $102.92 \pm 17.76$ & $127.93 \pm 35.08$ & $0.001^{*}$ \\
Biceps femoris & $107.20 \pm 18.70$ & $110.32 \pm 40.84$ & 0.878 \\
Gastrocnemius & $109.89 \pm 16.73$ & $123.73 \pm 43.32$ & 0.132 \\
Tibialis anterior & $108.69 \pm 25.30$ & $126.92 \pm 50.19$ & 0.086 \\
\hline
\end{tabular}

Mean \pm SD.

FW: Forward Walking, BW: Backward Walking.

${ }^{*}$ significant difference between FW and BW $(p<0.05)$.

은 각각 남자 7명, 여자 6 명, $24.2 \pm 1.0$ 세, $166.5 \pm 8.2 \mathrm{~cm}, 61.9 \pm 10.4 \mathrm{~kg}$ 이 었다.

보행의 시공간적 분석 결과, 모래지면에서 뒤로 걷기 시 한걸음길 이, 보행속도, 보행률, 양측 한발짝길이는 모래지면에서 앞으로 걷기 보다 유의하게 작았고 $(\mathrm{p}<0.05)$, 한걸음시간은 유의하게 컸다 $(\mathrm{p}<0.05)$ (Table 1). 하지만 디딤기, 흔듦기 및 양하지지지기 비율은 두 조건에서 유의한차이가 없었다 $(\mathrm{p}>0.05)$ (Table 1$)$.

보행의 운동형상학적 분석 결과, 모래지면에서 뒤로 걷기 시 엉덩 관절과 무릎관절의 관절가동범위는 모래지면에서 앞으로 걷기보다 유의하게 작았다 $(\mathrm{p}<0.05)($ Table 2$)$.

모래지면에서 뒤로 걷기 시 넙다리곧은근의 활성도는 앞으로 걷기 보다 유의하게 높았지만 $(\mathrm{p}<0.05)$, 넙다리두갈래근과 장딴지근, 앞정 강근의 활성도는 유의한 차이가 없었다 $(\mathrm{p}>0.05)$ (Table 3).

\section{고 찰}

본 연구는 정상 성인을 대상으로 모래지면에서 앞으로 걷기와 뒤로 걷기에 따른 보행의 시공간적 요소와 운동형상학적 특성 및 하지 근 활성도의 차이를 비교하였다. 본 연구에서 사용된 모래지면은 불안 정한 지면 중 하나로 평지에서의 보행과 다른 근활성도와 보행의 시 
공간적 요소 및 운동형상학적 특성을 보인다. 많은 선행연구들에서 불안정한 지면에서의 보행은 균형조절과 주의력 요구가 증가되기 때 문에 하지의 더 높은 근활성도가 요구되며, 한발짝길이와 보행속도의 감소와 같은 보행 패턴이 변화된다고 보고하였다. 38 -41 또한, 불안정한 지면에서는 운동정보를 빠르고 정확하게 처리하지 못하기 때문에 보 행 중 몸통의 기계적 동요가 나타난다.2 즉, 보행 중 안정성이 떨어지 기 때문에 안정성을 높이기 위한 전략으로 한발짝길이가 짧아지고, 보행속도가 느려지며, 양하지지지기 시간이 늘어나게 된다.28,43,44

본 연구결과 모래지면에서 뒤로 걷기 시 한걸음길이는 앞으로 걷 기 보다 유의하게 작았고, 한걸음시간은 유의하게 컸다. 이러한 결과 는 뒤로 걷기에 대한 균형의 제약을 해결하기 위한 반응으로 선행연 구에서도 본 연구의 결과와 같이 뒤로 걷기 동안은 앞으로 걷기와 비 교하여 감소된 한걸음길이와 증가된 한걸음시간이 보고되었다.45-47 모래지면에서 뒤로 걷기는 앞으로 걷기보다 보행속도가 유의하게 느 린 것으로 나타났다. 보행속도는 거리동안 걸린 시간 혹은 시간동안 걸은 거리로 계산되기 때문에 한걸음길이가 짧을수록 느려진다. 선 행연구에서도 뒤로 걷기는 앞으로 걷기보다 느린 보행속도를 나타냈 는데, 이는 시각적 정보의 부족과 시각적 피드백의 변경이 적절한 발 의 배치를 위한 하지의 운동 시너지 조절을 어렵게 하여 보행속도를 느리게 만든 것으로 사료된다.1348-50 또한, 앞으로 걷기와 다르게 뒤로 걷기는 시각 신호가 적거나 없기 때문에 신경근 조절과 고유수용성 감각, 보호반사에 더 많이 의존해야 하기 때문에 뒤로 걷기는 자세 변 화에 대한 근육반응 빈도와 양을 증가시키기 위해서 더 신경학적 피 드백이 필요하고, 한발짝길이, 한걸음길이, 보행률, 속도와 같은 보행 매개변수는 감소하는 보행 패턴의 변화를 초래한다.51 따라서 불안정 한 모래지면에서 뒤로 걷기 시 무게 중심이 고르지 않고, 시각 신호의 부족과 같은 균형의 제약으로 인해 한걸음길이, 한발짝길이, 보행률, 보행속도는 감소하고, 한걸음시간은 늘어나는 보행 패턴의 변화가 나 타난 것으로 생각된다.

보행의 운동형상학적 특성을 분석한 결과 모래지면에서 뒤로 걷 기는 앞으로 걷기에 비해 엉덩관절과 무릎관절의 관절가동범위가 유의하게 작은 것으로 나타났다. 모래에서 앞으로 걷기는 발목과 무 릎, 엉덩관절의 굽힘 증가가 관찰되는데 이는 흔듦기(swing phase) 중 발가락 들기(toe clearance)와 안전하게 앞으로 나아가기 위한 전략이 다. ${ }^{28}$ 일반적으로 뒤로 걷기는 앞으로 걷기와 다르게 발가락에서 발뒤 꿈치 순서로 시작된다(toe strike). 앞으로 걷기에서 디딤기(stance phase)는 발 뒤꿈치에서 시작하여(heel strike) 발가락을 떼면서 끝나 는 반면 뒤로 걷기는 발가락이 지면에 먼저 닿고, 발 뒤꿈치는 자세가 끝날 때 지면에서 떨어진다.52 이러한 뒤로 걷기의 내림차순 움직임은 무릎넙다리관절(patellofemoral joint)의 반응력을 감소시켜 무릎인대 의 편심성 부하를 감소시킨다. 또한, 무릎관절의 유해한 압축력과 스
트레스 힘을 감소시키도록 근육을 활성시키고, 무릎관절의 관절가 동범위의 감소를 동반한다.11,53 뒤로 걷기 시 무릎관절의 운동형상학 적 요소를 분석한 선행연구에 따르면, 뒤로 걷기는 무게중심이 무너 지는 것을 방지하기 위해 디딤기 동안 무릎 폄을 유지하고, 발 들기 (foot clearance)를 유지하기 위해 흔듦기 동안 굽힘을 유지한다. 이에 따라 뒤로 걷기는 시상면에서 앞으로 걷기에 비해 무릎관절의 관절 가동범위가 작아진다. ${ }^{53}$ 본 연구에서도 뒤로 걷기의 내림차순 움직임 에서 무릎관절은 디딤기에서 무게 중심 유지와 흔듦기에서 발 들기 를 유지해야 하기 때문에 관절가동범위가 적게 나온 것으로 사료된 다. 뒤로 걷기에서 엉덩관절은 무게중심을 조절하며," 다 디딤기에서 더 작은 폄각도를 보이고, 최대 굽힘 각도 역시 더 작 다. ${ }^{49}$ 이러한 결과로 뒤로 걷는 동안 감소된 엉덩관절의 관절가동범위 를 보인 것으로 생각되며 감소된 무릎관절과 엉덩관절의 폄각도는 한발짝길이와 보행속도를 감소시키는 것으로 생각된다.44

모래지면에서 뒤로 걷기 시 넙다리곧은근, 넙다리두갈래근, 장딴 지근, 앞정강근의 근활성도는 앞으로 걷기보다 모두 높았지만, 넙다 리곧은근에서만 유의한 차이가 나타났다. 일반적으로 앞으로 걷기 와 뒤로 걷기는 다른 근육 활성 패턴을 나타낸다. 장딴지근과 뒤넙다 리근은 앞으로 걷기 시에 한다리지지기(single support) 전반부에서 충 격을 감소시키기 위한 감속과 한다리지지기 후반부와 전흔듦기(pre swing)에서 질량중심선을 앞으로 이동하기 위한 가속역할을 하는 반 면에, 뒤로 걷기 시에는 한다리지지기 전반부에서 가속과 전흔듦기 에서 감속역할을 한다. ${ }^{4}$ 반대로 넙다리네갈래근은 앞으로 걷기 시 감속작용을 위해 편심성 수축을 하는 반면, 뒤로 걷기 시에는 등척 성 수축으로 무릎 안정제 역할과 함께 전흔듦기 동안에 가속작용을 위한 동심성 수축을 한다.49,52,54 즉, 앞으로 걷기에서 가속 작용을 한 근육은 뒤로 걷기에서 감속 작용을 하고, 앞으로 걷기에서 감속작용 을 한 근육은 뒤로 걷기에서 가속작용을 한다. 이때, 가속 작용을 위 한 동심성 수축은 감속 작용을 하기 위한 편심성 수축보다 더 높은 에너지와 많은 양의 운동단위 동원이 필요하기 때문에 뒤로 걷기에 서 가속작용을 하는 넙다리곧은근이 더 높은 근활성도를 보인 것으 로 생각된다.9.55 또한, 뒤로 걷는 동안 디딤기 초반에서는 엉덩관절의 폄이 나타나고, 디딤기 중반과 후반 및 흔듦기 초반에서는 엉덩관절 굽힘이 나타나는데, 엉덩관절은 흔듦기에서 발 들기를 위해 굽힘을 하기 때문에 넙다리곧은근과 바깥넓은근을 더 많이 사용해야 한 다. ${ }^{13,54}$ 트레드밀과 수중에서 앞으로 걷기와 뒤로 걷기를 진행한 선행 연구들에서는 앞으로 걷기 때 발가락떼기(toe off)에서 발목의 발바 닥굽힘을 통해 추진력을 발생시키지만 뒤로 걷기를 할 때는 발뒤꿈 치를 축으로 발등굽힘이 일어나기 때문에 앞정강근이 유의하게 높 은 근활성도를 보인다고 하였다.12,56 본 연구에서는 앞으로 걸을 때에 비해 뒤로 걸을 때 앞정강근의 근활성도가 높았지만, 유의한 차이는 
없었다. 모래지면에서 앞으로 걷을 때 발이 모래에서 미끄러지기 때 문에 세게 밀어야 하며, 신장-단축 주기로 인해 발목관절의 근육들을 더 많이 사용하기 때문에 ${ }^{23}$ 뒤로 걷기뿐만 아니라 앞으로 걷기에서도 높은 근활성도를 보여 앞으로 걷기와 뒤로 걷기를 비교하였을 때 앞 정강근의 근활성도에서 유의한 차이가 없었던 것으로 생각된다.

본 연구에서 사용한 모래지면은 충격 완화 성질로 인해 근육과 관 절에 걸리는 부하를 감소시켜 부상 위험을 줄이는 이점을 가지고 있 다. ${ }^{30,31}$ 또한, 뒤로 걷기는 발가락이 지면에 먼저 닿으면서 무릎에 주 는 충격과 관절의 스트레스를 줄인다.53 본 연구 결과 모래지면에서 뒤로 걸을 때는 보행 변수를 변화시켜 안정성을 높이는 전략이 사용 되며, 이와 함께 넙다리곧은근을 선택적으로 활성시키는 것을 확인 하였다. 또한, 모래지면에서 뒤로 걷기는 적은 관절가동범위로 넙다 리곧은근을 효과적으로 활성시킬 수 있는 것으로 나타났다. 따라서 무릎관절과 엉덩관절의 관절가동범위에 제한이 있는 환자의 재활운 동에 넙다리곧은근의 근력강화를 위한 치료전략으로 이용할 수 있 을 것이며, 스포츠 분야에서 하지 관절의 부하를 줄이면서 선택적으 로 넙다리곧은근을 활성시키기 위한 훈련 프로그램으로 이용할 수 있을 것이다. 즉, 넙다리네갈래근을 활성시키기 위한 뒤로 걷기에 불 안정한 지면으로 모래를 적용하는데 임상적 기초 자료가 될 것으로 사료된다. 본 연구는 다음과 같은 제한점이 있다. 첫째, 20 대 정상 성인 만을 대상으로 연구하여 일반화하기 어려움이 있다. 둘째, 휴대용 보 행분석시스템으로 모래에서 발목관절을 측정할 때, 모래의 깊이 때 문에 발이 모래 속으로 빠져 발생하는 노이즈로 인해 앞으로 걷기와 뒤로 걷기 시 발목의 관절가동범위 데이터를 추출할 수 없었다. 또한, 휴대용 보행분석시스템과 영상을 활용하여 보행주기를 나눠 분석하 려 했지만, 모래 속으로 발이 빠져 보행주기를 정확히 구분하기 어려 워 근육활성도를 보행주기별로 구분할 수 없었다. 셋째, 본 연구는 단 면연구로 중재적 관점에서 모래에서 뒤로 걷기의 지속적인 효과를 파악할 수 없었다. 향후 연구에서는 다양한 연령과 환자들을 대상으 로 모래에서 뒤로 걷기 운동의 중재적 효과를 파악하고, 발목의 관절 가동범위를 비교할 필요가 있다.

\section{REFERENCES}

1. Galley PM, Foster AL. Human movement: an introductory text for physiotherapy students. New York, Churchill Livingstone, 1987:228-37.

2. Kim JH, Oh TY. The comparison of characteristics of foot pressure between treadmill and ground walking in normal person. Korean Soc Phys Med. 2010;5(1):53-61.

3. Bohannon RW. Gait performance of hemiparetic stroke patients: selected variables. Arch Phys Med Rehabil. 1987;68(11):777-81.

4. Norkin CC, Levangie PK. Joint structure and function. Philadelphia, FA Davis Co, 1992:60-70.
5. Lee DH, Park HW, Han SB et al. Kinematics in normal and pathological gait. J Korean Orthop Res Soc. 2004;7(2):169-77.

6. Albensi RJ, Nyland J, Caborn DNM. The relationship of body weight and clinical foot and ankle measurements to the heel forces of forward and backward walking. J Athl Train. 1999;34(4):328-33.

7. Winter DA. The biomechanics and motor control of human gait. 2nd. Ontario, University of Waterloo Press, 1988:1-9.

8. Winter DA, Pluck N, Yang JF. Backward walking: a simple reversal of forward walking? J Mot Behav. 1989;21(3):291-305.

9. Moriello G, Pathare N, Cirone C et al. Comparison of forward versus backward walking using body weight supported treadmill training in an individual with a spinal cord injury: a single subject design. Physiother Theory Pract. 2014;30(1):29-37.

10. Gray GW. Chain reaction successful strategies for closed chain testing and rehabilitation. Minnesota, Wynn Marketing, 1990:80-98.

11. Flynn TW, Soutas Little RW. Mechanical power and muscle action during forward and backward running. J Orthop Sports Phys Ther. 1993;17 (2):108-12.

12. Cipriani D, Armstrong C, Gaul S. Backwards walking at three levels of treadmill inclination: an electromyographic and kinematic analysis. J Orthop Sports Phys Ther. 1995;22(3):95-102.

13. Grasso R, Bianchi L, Lacquaniti. Motor patterns for human gait: backward versus forward locomotion. J Neurophysiol. 1998;80(4):1868-85.

14. P DeVita, J Stribling. Low extremity joint kinetics and energetics during backward running. Med Sci Sports Exerc. 1991;23(5):602-10.

15. Nadeau S, Amblard B, Mesure S et al. Head and trunk stabilization strategies during forward and backward walking in healthy adults. Gait Posture. 2003;18(3):134-42.

16. Hao WY, Chen Y. Backward walking training improves balance in schoolaged boys. Sports Med Arthrosc Rehabil Ther Technol. 2011;3:24.

17. Cho KK, Kim YS, Cho SH. The comparative analysis of EMG depending on variations of speed in forward walking and backward walking. Korean J Sport Biomech. 2007;17(3):1-10.

18. Kang HK, Seo HD, Lee KW et al. The Effects of elliptical training, treadmill walking and overground walking on muscle activation of lower extremity. Journal of Special Education Rehabilitation Science. 2012:51 (1):253-66.

19. Kim JW, Kweon HK. Effects of unstable surface combined exercise on fall-related fitness and gait function in elderly women. J Korean Soc Environ Eng. 2018;25(1):52-61.

20. Kin GR, Song MS. Effects of a stim up mat walking exercise program on balance, gait function and joint motion range of the frail elderly. J Korean Acad Community Health Nurs. 2019;30(1):47-56.

21. Lee GI, Jeon JJ, Hahm SC. A comparison of the effects of barefoot walking and sneakers walking on a sandy beach on pain, disability, motor function, sleep satisfaction, and quality of life in the elderly with low back pain. Journal of The Korean Society of Integrative Medicine. 2020; 8(4): 29-38

22. Song GB, Park EC. The effects of balance training on balance pad and sand on balance and gait ability in stroke patients. J Korean Soc Phys Med. 2016;11(1):45-52.

23. Morrison K, Braham R, Dawson B et al. Effect of a sand or firm-surface walking program on health, strength, and fitness in women 60-75 years old. J Aging Phys Act. 2009;17(2):196-209. 
24. Jafarnezhadgero A, Fatollahi A, Amirzadeh N et al. Ground reaction forces and muscle activity while walking on sand versus stable ground in individuals with pronated feet compared with healthy controls. PLoS One. 2019;14(9):e0223219.

25. Lejeune TM, Willems PA, Heglund NC. Mechanics and energetics of human locomotion on sand. J Exp Biol. 1998;201(13):2071-80.

26. Pinnington HC, Lloyd DG, Besier TF. Kinematic and electromyography analysis of submaximal differences running on a firm surface compared with soft, dry sand. Eur J Appl Physiol. 2005;94(3):242-53.

27. Kwak HS. A case study of the application of sand-box play therapy on children with the emotional \& behavioral disorder. Korea National University of Education. Dissertaion of Master's Degree. 2003.

28. Van den Berg ME, Barr CJ, McLoughlin JV et al. Effect of walking on sand on gait kinematics in individuals with multiple sclerosis. Mult Scler Relat Disord. 2017;16:15-21.

29. Thies SB, Richardson JK, Ashton Miller JA. Effects of surface irregularity and lighting on step variability during gait: a study in healthy young and older women. Gait Posture. 2005;22(1):26-31.

30. Impellizzeri FM, Rampinini E, Castagna C et al. Effect of plyometric training on sand versus grass on muscle soreness and jumping and sprinting ability in soccer players. Br J Sports Med. 2008;42(1):42-6.

31. Miyama M, Nosaka K. Influence of surface on muscle damage and soreness induced by consecutive drop jumps. J Strength Cond Res. 2004;18 (2):206-11.

32. Faul F, Erdfelder E, Lang AG et al. G*Power 3: a flexible statistical power analysis program for the social, behavioral, and biomedical sciences. Behav Res Methods. 2007;39(2):175-91.

33. Basta D, Rossi Izquierdo M, Soto Varela A et al. Efficacy of a vibrotactile neurofeedback training in stance and gait conditions for the treatment of balance deficits: a double-blind, placebo-controlled multicenter study. Otol Neurotol. 2011;32(9):1492-9.

34. Aminian K, Najafi B, Bula C et al. Spatio-temporal parameters of gait measured by an ambulatory system using miniature gyroscopes. J Biomech. 2002;35(5):689-99.

35. Najafi B, Helbostad JL, Moe Nilssen R et al. Does walking strategy in older people change as a function of walking distance? Gait Posture. 2009;29(2):261-6.

36. Yeo SS, Park GY. Accuracy verification of spatio-temporal and kinematic parameters for gait using inertial measurement unit system. Sensors. 2020;20(5):1343.

37. Winter DA, Yack HJ. EMG profiles during normal human walking: stride-to-stride and inter-subject variability. Electroencephalogr Clin Neurophysiol. 1987;67(5):402-11.

38. Marigold DS, Patla AE. Age-related changes in gait for multi-surface terrain. Gait Posture. 2008;27:689-96.

39. Hak PT, Hodzovic E, Hickey B. The nature and prevalence of injury during crossfit training. J Strength Cond Res. 2013.

40. Nilsagard Y, Lundholm C, Denison E et al. Predicting accidental falls in people with multiple sclerosis: a longitudinal study. Clin Rehabil. 2009; 23(3):259-69.

41. Lee KJ, Lee SW, Lee SW et al. The effect of low extremity strengthening enhanced gait mat training on unstable surface on gait parameter and low extremity strength in elderly. J Spec Educ Rehabil Sci. 2011;50(4): 419-35.

42. MacLellan MJ, Patla AE. Adaptations of walking pattern on a compliant surface to regulate dynamic stability. Exp Brain Res. 2006;173(3):52130.

43. Seo HW, Kim MC. Study on the correlation between muscle activity of lower extremity and sway speed of chronic stroke patients according to unstable surface training. Journal of the Korean Society of Integrative Medicine. 2013;1(4):75-83.

44. Peter V, William D, Bart G. Peroneal reaction times and eversion motor response in healthy and unstable ankles. J Athl Train. 2002;37(4)475-80.

45. Myatt G, Baxter R, Dougherty R et al. The cardiopulmonary cost of backward walking at selected speeds. J Orthop Sports Phys Ther. 1995; 21(3):132-8.

46. Williford HN, Olson MS, Gauger S et al. Cardiovascular and metabolic costs of forward, backward, and lateral motion. Med Sci Sports Exerc. 1998;30(9):1419-23.

47. Kurz MJ, Wilson TW, Arpin DJ. Stride-time variability and sensorimotor cortical activation during walking. Neuroimage. 2012;59(2):1602-7.

48. Reynolds RF, Day BL. Visual guidance of the human foot during a step. J Physiol. 2005;569(2):677-84.

49. Lee MH, Kim JY, Son JS et al. Kinematic and kinetic analysis during forward and backward walking. Gait Posture. 2013;38(4):674-8.

50. Kim SG, Ryu YU, Je HD et al. Backward walking treadmill therapy can improve walking ability in children with spastic cerebral palsy: a pilot study. Int J Rehabil Res. 2013;36(3):246-52.

51. Thomas MA, Fast A. One step forward and two steps back: the dangers of walking backwards in therapy. Am J Phys Med Rehabil. 2000;79(5): 459-61.

52. Joshi S, Vij JS, Singh SK. Retrowalking: a new concept in physiotherapy and rehabilitation. Int J Sci Res. 2015;4(10):152-6.

53. Hasegawa M, Chin T, Oki S et al. Effects of methods of descending stairs forwards versus backwards on knee joint force in patients with osteoarthritis of the knee: a clinical controlled study. BMC Sports Sci Med Rehabil. 2010;2(1):1-7.

54. Jansen K, Groote FD, Massaad F et al. Similar muscles contribute to horizontal and vertical acceleration of center of mass in forward and backward walking: implications for neural control. J Neurophysiol. 2012;107 (12):3385-96.

55. Hody S, Croisier JL, Bury T et al. Eccentric muscle contractions: risks and benefits. Front Physiol. 2019;10:536.

56. Masumoto K, Takasugi S, Hotta N et al. A comparison of muscle activity and heart rate response during backward and forward walking on an underwater treadmill. Gait Posture. 2017;25(2): 222-8. 